\title{
Molecular and Kinetic Characterization of the Fermentative Behavior of Saccharomyces cerevisiae Strains Isolated from North Patagonia
}

\author{
Adriana Beatriz Simes', Ramona del Carmen Maturano², Valentín Tassile1, \\ Adriana Catalina Caballero ${ }^{1,2}$, Silvana María del Mónaco ${ }^{2 *}$ \\ ${ }^{1}$ Facultad de Ciencias y Tecnología de los Alimentos, Universidad Nacional del Comahue (UNCo), Villa Regina, \\ Argentina \\ ${ }^{2}$ Grupo de Enología, Instituto de Investigación y Desarrollo en Ingeniería de Procesos, Biotecnología y Energías \\ Alternativas (PROBIEN-Consejo Nacional de Investigaciones Científicas y Técnicas, CONICET), Facultad de \\ Ingeniería, Universidad Nacional del Comahue (UNCo), Neuquén, Argentina \\ Email: "silmdm@yahoo.com, "silvanadelmonaco@gmail.com
}

Received 17 June 2016; accepted 16 August 2016; published 19 August 2016

Copyright (C) 2016 by authors and Scientific Research Publishing Inc.

This work is licensed under the Creative Commons Attribution International License (CC BY).

http://creativecommons.org/licenses/by/4.0/

(c) (i) Open Access

\section{Abstract}

At present, Argentina does not count with a production of indigenous yeast strains with suitable technological and oenological features to be used in the regional winery industry. Isolation and molecular characterization of these microorganisms and its fermentation attributes would be relevant to the sustainable development of the activity in the country and to recognize and preserve the biodiversity of the region. Eight strains isolated from grapes and musts from the North Patagonian region and genetically identified as Saccharomyces cerevisiae, were studied for their fermentation behavior, emphasizing in hexose transport through the plasma membrane, which is the limiting step of the process. Thus, sugar consumption profiles were analyzed in different media at laboratory scale, to be subsequently applied to the fermentation of natural musts. Three of the eight initial strains were selected, named ÑNM10, ÑIF8 and ÑMN16 according to their fermentation profiles. The expression of hexose transporters during fermentations revealed interesting differences in the response of each strain to sugar consumption, where transporters HXT2 and HXT5 showed significant changes in expression in Patagonian strains, which are normally associated to endurance to culture stress conditions. The results obtained by combining the characteristics studied, at molecular and physiological level, are extremely encouraging. Native strain ÑMN16, showed a high potential for application in local winemaking. Assays carried out on a pilot scale will determine the feasibility of applying this strain with promising technological features at industrial scale.

"Corresponding author.

How to cite this paper: Simes, A.B., Maturano, R.delC., Tassile, V., Caballero, A.C. and del Mónaco, S.M. (2016) Molecular and Kinetic Characterization of the Fermentative Behavior of Saccharomyces cerevisiae Strains Isolated from North Patagonia. Advances in Microbiology, 6, 733-744. http://dx.doi.org/10.4236/aim.2016.69072 


\section{Keywords}

\section{Fermentation, Wine, Saccharomyces cerevisiae, Hexose Transporters}

\section{Introduction}

Winemaking is a complex enological process involving different microbial groups, where yeasts play a fundamental role in Alcoholic Fermentation (AF), the critical phase of this process [1]. Yeasts convert the principal grape sugars (glucose and fructose) into ethanol, carbon dioxide and different primary metabolites that confer a particular character to wine [2] [3]. Grapes contain equal amounts of both hexoses, reaching a total concentration of 160 to $300 \mathrm{~g} / \mathrm{L}$. Saccharomyces cerevisiae, the yeast species commonly involved in conducting AF, is a glucophilic yeast, preferring glucose instead of fructose. During this process, glucose is consumed faster than fructose and therefore the latter becomes the main sugar present in the final stages. Yeasts should use this nonpreferred sugar after starvation periods, low levels of nitrogen and in presence of high concentrations of ethanol [4]. These environmental conditions of stress can cause slow fermentations; thus the ability of yeasts for consuming fructose is a strain-dependent property that would guarantee the maintenance of high fermentative rates until the end of the productive development. That is why this metabolic trait is a very important criterion for selection of yeasts with oenological potential aiming to achieve an adequate drying of the must [5] [6].

Utilization of hexoses by yeasts depends on expression of transporters in the plasmatic membrane, since the internalization of sugar is the limiting step for its subsequent metabolization. Uptake of hexoses in Saccharomyces is mediated by specific transporters belonging to a superfamily of facilitators of flow for monosaccharides with twelve transmembrane domains, denominated HXT [7] [8]. Until now, 18 genes involved in transport of hexoses have been identified: HXT1-HXT17 and GAL2, coding for Hxt1p-Hxt17p and Gal2p transporters, respectively [4]. However, under normal conditions the incorporation of hexoses into the cell is conduced only by six transporters: Hxt1p to Hxt6/7p, which differ considerably in its affinity and specificity for substrates [9] [10].

The expression of a single $H X T$ gene depends on several environmental factors, where medium hexose concentration detected by the yeast cell is an important signal. Transporters with moderate (Htx2p, Htx4p y Htx5p) and high (Hxt6p y Hxt7p) affinity are induced by small amounts of glucose and repressed by high amounts of this hexose, while low affinity ones (Hxt1p y Hxt3p) are induced by high glucose concentrations or only are feebly regulated by the concentration of this sugar [4] [11]. Both groups, low and high affinity transporters, demonstrated to have more affinity for glucose than for fructose and this difference can affect the utilization rates of those hexoses. The quality of the fermentation conducted by $S$. cerevisiae is strongly influenced by the specificity of the transporters expressed in each strain.

The Patagonian region, located at $37^{\circ} 5^{\prime}$ and $40^{\circ} 5^{\prime}$ southern latitude, is a wine-producing region in Argentina and one of the most Southern regions dedicated to this activity in the world. This area presents advantageous agro-ecological conditions for high quality vitiviniculture [12] and its production is mainly represented by young dry wines from red Vitis vinifera varieties, such as Merlot and Pinot noir, which have met in this region optimal conditions for their full oenological expression [13]. However, the pressure of an increasingly competitive international market and consumer demands for new styles of wines impose challenges to Patagonian winemakers that require technological innovation. In recent years, there has been a growing interest among wine-researchers and winemakers towards the selection of autochthonous strains to develop starter cultures that are potentially better adapted to grow in a specific grape must, reflecting the biodiversity of a given region and supporting the notion that specific native yeast strains can be associated with a terroir [14]-[16]. Previous microbiological studies in our region revealed a geographical structuration of indigenous populations of $S$. cerevisiae associated to local vinifications [17]. The maintenance of the biological patrimony and the exploitation of the biodiversity of indigenous fermentative strains is essential to obtain yeasts with specific phenotypes that potentially develop the typical flavour and aroma of wines from particular grapevine cultivars and to ensure the conservation of gene pools of technological importance [2] [14].

In this framework, the aim of the present work was to characterize hexose consumption by Saccharomyces cerevisiae strains isolated from wineries of the North Patagonian region, focusing particularly on fructose meta- 
bolization. In addition, the molecular expression of the hexose transporters was evaluated along the fermentation in order to detect individuals with better uptake profiles.

\section{Materials and Methods}

\subsection{Samples}

Merlot and Malbec varietal grapes and musts were obtained from a cellar placed in the Neuquén province, (latitude: $38^{\circ} 56^{\prime} 09.06^{\prime \prime S}$ longitude: $68^{\circ} 03^{\prime} 36.87^{\prime \prime} \mathrm{W}$ altitude: $338 \mathrm{~m}$ ), in the North Patagonian region, Argentina. Grape samples were collected aseptically from 4 years old vineyards at vintage using a cross sampling protocol, where fifteen grape bunches corresponding to 15 different plants were collected in each vineyard for each varietal. Grape bunches were transferred to sterile containers. Grape musts were obtained during natural AF at pilot scale $(200 \mathrm{~L})$ or during controlled AF (using commercial starters) at industrial scale. Samples were collected by the enologist in sterile glass containers $(1 \mathrm{~L})$ after the remount process (to ensure a homogeneous mixture), in three different stages: beginning (approximately 12 - $14{ }^{\circ} \mathrm{Bmé}$ ), middle (approximately $6{ }^{\circ} \mathrm{Bmé}$ ) and at the end ( $\left.<0{ }^{\circ} \mathrm{Bmé}\right)$ of fermentation. Samples were transported to the laboratory and conserved at $4{ }^{\circ} \mathrm{C}$ until processing.

\subsection{Yeast Isolation and Molecular Characterization}

Yeasts associated to grape surfaces were obtained by shaking of berries $(180 \mathrm{rpm})$ in sterile water for $1 \mathrm{~h}$ followed by sonication (30 sec $\times 3,300$ Watts). Aliquots $(1 \mathrm{~mL})$ of suspensions from grapes or musts were subjected to successive dilutions and plated by dissemination in surface in GPY agar (pluripeptone $0.5 \%$, yeast extract $0.5 \%$, Glucose $2 \%$, Agar 2\%), adjusted to $\mathrm{pH} 4.5$ - 5. Plates were incubated for 48 to $72 \mathrm{~h}$ at $26^{\circ} \mathrm{C}$ until colonies developed. The isolate colonies were characterized and selected according to their morphology and their frequencies of appearance. Yeasts were identified by restriction analysis (PCR-RFLP) of the region encompassing the ITS1, 5.8SrRNA and ITS2 (5.8S-ITS region) as described in [18]. PCR-RFLP patterns obtained for each isolate were compared with those of reference strains available in the www.yeast-id.org database. Yeast identifications were confirmed by sequencing the D1/D2 domain of the 26S rRNA gene [19] [20]. The sequences were edited and assembled using MEGA6 ${ }^{\mathrm{TM}}$ software [21] and then subjected to a GenBank BLASTN. For isolates belonging to Saccharomyces cerevisiae species, an analysis of polymorphism of restriction fragments of mitochondrial DNA using endonuclease Hinf I (DNAmit RFLP) was conducted [22].

\subsection{Strains and Culture Conditions}

S. cerevisiae isolates were stored in glycerol $(20 \% \mathrm{v} / \mathrm{v})$ as cryoprotective agent at $-20^{\circ} \mathrm{C}$. When needed, cells were cultured in GPY medium (pluripeptone $0.5 \%$, yeast extract $0.5 \%$, Glucose $2 \%$ ), for 48 hs at $28^{\circ} \mathrm{C}$. In each treatment performed to the native yeasts, a commercial strain commonly used as starter in local wineries, Saccharomyces cerevisiae BC1118, was used as control standard. This strain was selected by its known technological performance and metabolism at the molecular level.

\subsection{Microfermentations}

After 48 hours at $28^{\circ} \mathrm{C}$ activation in GPY broth, each pre-inoculum of the analyzed yeast strain was transferred to vials with distilled water for 24 hs to induce a cell starvation condition. Subsequently, cell suspensions were used to inoculate individually experimental media in an initial cell concentration of $\left.10^{5} \mathrm{cfu} / \mathrm{mL}: 1\right)$ YNB medium (Yeast Nitrogen Base with amino acids and ammonium sulphate (Difco), 0.67\%), called basal medium (BM), supplemented with 20\% glucose (w/v) (BMG); 2); 20\% fructose (w/v) (BMF); 3) a mixture $10 \%(w / v)$ of both sugars (BMGF); 4) Pinot noir natural must from the Comahue region, vintages 2012 and 2013. Two volumes of fermentation were evaluated: $10 \mathrm{~mL}$ of BMG $(n=3)$, BMF $(n=3)$, and BMGF $(n=4), 60 \mathrm{ml}$ of BMGF $(n=4)$ and $60 \mathrm{ml}$ Pinot noir must $(\mathrm{n}=3)$. All fermentation processes were conducted for 21 days at $28^{\circ} \mathrm{C}$.

\subsection{Statistical Treatment and Modelling}

Statistical modeling and data treatment were made under the "nlme" library of R statistical software [23]. Relative weight loss of $\mathrm{CO}_{2}$ production during fermentation was modeled by the Gompertz reparametrized equation proposed by [24], where: 


$$
y=A \times\left(\exp \left(-\exp \left(\left(\frac{m \times 2.718282}{A}\right) *(\lambda-x)+1\right)\right)\right)
$$

being " $A$ " the maximum asymptote of the modeled curve, " $m$ " the exchange rate during the exponential phase, " $\lambda$ " the determinant of the lag phase, $y=$ Weight loss $\left(\mathrm{g} \cdot \mathrm{L}^{-1}\right)$ and $x=$ time (days). The level of significance of parameters $A, m$ and $\lambda$ for each strain was analyzed by the method of Wald and pairs of means comparison through LSD test.

Sugar consumption was assessed by modeling glucose and fructose concentration by the equation developed by [25] for reducing the concentration of chemicals in foods, modified by [26] to adjust the surface color parameters $L^{*}, a^{*}$ and $b^{*}$ on foods over time. So modified, this equation allowed the convergence of data of residual sugars in broth and must. The model has the following form:

$$
S_{t}=S_{0} \cdot \mathrm{e}^{-K c^{*} t}+D
$$

where $D$ is the lower asymptote (parameter $t \rightarrow \infty$ ), $S_{0}$ is the initial specific value for each setting, and $K c$ is the rate of change in days ${ }^{-1}$.

Using this equation for modelling remaining hexoses in BMGF and must, these parameters take a similar meaning, where $D$ describes the lower asymptote model in grams liter $^{-1}, S_{0}$ is the initial concentration modelled for each sugar, also in grams liter ${ }^{-1}$ and $K c$ the rate of decline in days ${ }^{-1}$.

Again, data were analyzed statistically using the program R (R Core Team 2014) [23] with "nlme” package, according to a nonlinear mixed effects model and adjusted by Maximum Likelihood.

\subsection{Molecular Analysis of Expression of Hexose Transporters}

Total yeast RNA was isolated at 0, 7, 14 and 21 days of fermentation in synthetic must (BMGF) using the MasterPure ${ }^{\mathrm{TM}}$ Yeast RNA Purification Kit” Epicentre ${ }^{\circledR}$, Illumina ${ }^{\circledR}$ commercial kit. Isolated RNAs were stored at $-80^{\circ} \mathrm{C}$. Reverse transcription of mRNA was achieved using qScript ${ }^{\mathrm{TM}} \mathrm{CDNA}$ SuperMix (Quanta Biosciences ${ }^{\mathrm{TM}}$ ) kit for 5 minutes at $25^{\circ} \mathrm{C}, 30$ minutes at $42^{\circ} \mathrm{C}, 5 \mathrm{~min} 85^{\circ} \mathrm{C}$ and a final cycle at $4^{\circ} \mathrm{C}$, in a Progene thermocycler (Techne, Cambridge, UK). cDNA of Hxt1p to Hxt6/7p transporters were amplified by PCR using specific primers described by Lee and Lee (2008), [27]. Primers for actin protein were used as an internal control. The reaction was carried out for $15 \mathrm{~min}$ at $95^{\circ} \mathrm{C}, 30$ seconds at $94^{\circ} \mathrm{C}, 30$ seconds at $58^{\circ} \mathrm{C}$ and 30 seconds at $72^{\circ} \mathrm{C}$, and a final extension step $72^{\circ} \mathrm{C}$ for $10 \mathrm{~min}$. PCR products were separated in a $1.5 \%(\mathrm{w} / \mathrm{v})$ agarose gel, and DNA bands were visualized staining with GelRed ${ }^{\mathrm{TM}}$. A 100 bp DNA ladder was used as a molecular weight marker (Genbiotech, Argentina). Semi-quantitative analysis of the expression of each hexose transporter was carried out quantifying its signal intensity against actin signal in different steps along the fermentations using 1.37 V Densitometric Software ImageJ (NIH, USA). Statistical analysis of the relative intensities of the bands in agarose gels was performed with the Statistica 8.0 software. Average of this rates and its relative standard deviation was calculated with one-way ANOVA module and homogeneous groups through LSD test.

\section{Results}

\subsection{Strain Selection}

From the isolations obtained in the North Patagonian region in the 2005/2006 vintages from Merlot and Malbec varietals, $110 \mathrm{~S}$. cerevisiae strains were identified at the species level. Almost half of the S. cerevisiae strains were identified as starter cultures (49\%), as expected in the controlled fermentations that were deliberately inoculated. However, starter profiles were also identified from natural fermentation samples, which suggest the presence of those "contaminants" in cellar surfaces. From the native strains detected (51\%), eight individuals from different mitochondrial profiles were selected to continue this work. Notation for the selected strains was developed as follows: first letter: storage of origin ( $\tilde{\mathrm{N}}$ : Añelo cellar); second letter: type of winemaking ( $\mathrm{N}$, natural; I, Inoculated); third letter: stage of the fermentation (I, initial, M, medium, F, final); the number indicates the order of isolation within each series. Therefore, studies continued with ÑNM10, ÑIF5, ÑNF13, ÑNF9, ÑNF8, ÑNM16, ÑIF8, and ÑNF7 native strains. In addition, each assay performed was contrasted with results obtained with commercial strain S. cerevisiae BC1118. 


\subsection{Microvinification in Synthetic and Natural Must}

Native and control S. cerevisiae evaluated strains were studied according to their fermentation profiles. $\mathrm{CO}_{2}$ levels released during microvinifications were assessed by weight loss of the fermenters, in $\mathrm{g} \cdot \mathrm{L}^{-1}$ for each of the culture broths (BMG, BMF and BMGF) during 21 days. Data of weight loss of each fermenter was treated statistically following the proposed model of [24], and using the Gompertz reparametrized equation where parameters describing growth curves were obtained with $\mathrm{R}$ statistical program (R Core Team 2014), under the "nlme" package. Values obtained with the statistical analysis for parameters $A$ (the maximum asymptote of the modeled curve), $m$ (the exchange rate during the exponential phase) and $\lambda$ (the determinant of the lag phase) for each strain in synthetic media, standard deviations and homogeneous groups are shown in Table 1 . The use of

Table 1. Modelled growth parameters obtained in BMGF, BMF and BMGF broths.

\begin{tabular}{|c|c|c|c|c|}
\hline \multicolumn{5}{|c|}{ Gompertz equation parameters } \\
\hline & & $A$ & $M$ & $\lambda$ \\
\hline \multirow{9}{*}{$B M G$} & $\tilde{N} N M 10$ & $130.589 \pm 25.705^{\mathrm{d}}$ & $7.089 \pm 1.129^{c}$ & $0.329 \pm 0.563^{\mathrm{a}}$ \\
\hline & $\tilde{N} I F 8$ & $233.378 \pm 25.8485^{a}$ & $9.785 \pm 1.087^{\mathrm{ab}}$ & $0.367 \pm 0.446^{\mathrm{a}}$ \\
\hline & $\tilde{N} N F 8$ & $135.326 \pm 28.842^{\text {cd }}$ & $6.600 \pm 1.238^{c}$ & $0.471 \pm 0.664^{\mathrm{a}}$ \\
\hline & $\tilde{N} N M 16$ & $136.820 \pm 25.467^{\mathrm{cd}}$ & $8.514 \pm 1.150^{\mathrm{abc}}$ & $0.348 \pm 0.506^{\mathrm{a}}$ \\
\hline & $\tilde{N} I F 5$ & $134.848 \pm 28.452^{\mathrm{cd}}$ & $7.867 \pm 1.274^{\mathrm{bc}}$ & $-0.211 \pm 0.618^{\mathrm{a}}$ \\
\hline & $\tilde{N} N F 7$ & $212.585 \pm 28.692^{\mathrm{ab}}$ & $10.407 \pm 1.238^{\mathrm{a}}$ & $0.250 \pm 0.499^{\mathrm{a}}$ \\
\hline & $\tilde{N} N F 9$ & $144.933 \pm 28.436^{\mathrm{cd}}$ & $8.609 \pm 1.272^{\mathrm{abc}}$ & $0.300 \pm 0.576^{\mathrm{a}}$ \\
\hline & $\tilde{N} N F 13$ & $118.745 \pm 28.350^{\mathrm{d}}$ & $9.893 \pm 1.419^{\mathrm{ab}}$ & $0.380 \pm 0.569^{\mathrm{a}}$ \\
\hline & BC1118 & $174.474 \pm 18.074^{\mathrm{bc}}$ & $8.733 \pm 0.779^{\mathrm{abc}}$ & $0.055 \pm 0.340^{\mathrm{a}}$ \\
\hline \multirow{9}{*}{$B M F$} & $\tilde{N} N M 10$ & $156.549 \pm 27.947^{\mathrm{a}}$ & $8.101 \pm 1.813^{\mathrm{a}}$ & $0.226 \pm 0.510^{\mathrm{a}}$ \\
\hline & $\tilde{N} I F 8$ & $99.033 \pm 27.791^{\mathrm{bc}}$ & $7.376 \pm 1.849^{\mathrm{a}}$ & $0.294 \pm 0.576^{\mathrm{a}}$ \\
\hline & $\tilde{N} N F 8$ & $147.114 \pm 31.280^{\mathrm{ab}}$ & $7.664 \pm 2.034^{\mathrm{a}}$ & $0.371 \pm 0.608^{\mathrm{a}}$ \\
\hline & $\tilde{N} N M 16$ & $139.636 \pm 27.801^{\mathrm{ab}}$ & $9.731 \pm 1.844^{\mathrm{a}}$ & $-0.854 \pm 0.500^{b}$ \\
\hline & $\tilde{N} I F 5$ & $60.203 \pm 31.012^{c}$ & $6.185 \pm 2.153^{\mathrm{a}}$ & $0.167 \pm 0.802^{\mathrm{ab}}$ \\
\hline & $\tilde{N} N F 7$ & $152.803 \pm 31.164^{\mathrm{a}}$ & $8.818 \pm 2.042^{\mathrm{a}}$ & $-0.085 \pm 0.568^{\mathrm{ab}}$ \\
\hline & ÑNF9 & $142.220 \pm 31.093^{\mathrm{ab}}$ & $9.411 \pm 2.067^{\mathrm{a}}$ & $0.132 \pm 0.568^{\mathrm{ab}}$ \\
\hline & $\tilde{N} N F 13$ & $106.049 \pm 31.034^{\mathrm{abc}}$ & $9.007 \pm 2.115^{\mathrm{a}}$ & $0.226 \pm 0609^{\mathrm{ab}}$ \\
\hline & BC1118 & $130.955 \pm 19.697^{\mathrm{ab}}$ & $7.299 \pm 1.284^{\mathrm{a}}$ & $-0.428 \pm 0.381^{\mathrm{ab}}$ \\
\hline \multirow{9}{*}{$B M G F$} & $\tilde{N N M 10}$ & $179.512 \pm 18.718^{a}$ & $8.342 \pm 1.477^{\mathrm{ab}}$ & $-0.061 \pm 0.593^{a b}$ \\
\hline & $\tilde{N} I F 8$ & $127.483 \pm 18.061^{\mathrm{c}}$ & $7.367 \pm 1.515^{\mathrm{ab}}$ & $-0.569 \pm 0.700^{\mathrm{b}}$ \\
\hline & $\tilde{N} N F 8$ & $97.131 \pm 20.218^{\mathrm{cd}}$ & $8.097 \pm 1.874^{\mathrm{ab}}$ & $1.176 \pm 0.801^{\mathrm{a}}$ \\
\hline & $\tilde{N} N M 16$ & $137.383 \pm 18.063^{\mathrm{bc}}$ & $8.795 \pm 1.531^{\mathrm{ab}}$ & $0.118 \pm 0.612^{\mathrm{ab}}$ \\
\hline & $\tilde{N} I F 5$ & $82.338 \pm 20.198^{\mathrm{d}}$ & $5.668 \pm 1.726^{\mathrm{b}}$ & $-0.589 \pm 0.944^{\mathrm{b}}$ \\
\hline & $\tilde{N} N F 7$ & $88.338 \pm 19.770^{\mathrm{d}}$ & $6.613 \pm 1.767^{\mathrm{ab}}$ & $0.084 \pm 0.901^{\mathrm{ab}}$ \\
\hline & $\tilde{N} N F 9$ & $171.468 \pm 20.733^{\mathrm{ab}}$ & $9.109 \pm 1.678^{\mathrm{a}}$ & $0.252 \pm 0.660^{\mathrm{ab}}$ \\
\hline & $\tilde{N} N F 13$ & $76.179 \pm 19.861^{d}$ & $7.971 \pm 2.051^{\mathrm{ab}}$ & $0.798 \pm 0.945^{\mathrm{ab}}$ \\
\hline & BC1118 & $165.058 \pm 12.860^{\mathrm{ab}}$ & $9.249 \pm 1.062^{\mathrm{a}}$ & $0.186 \pm 0.410^{\mathrm{ab}}$ \\
\hline
\end{tabular}

Gompertz reparametrized equation parameters obtained by modelling accumulated weightloss in YNB-Glucose 20\% (BMG), YNB-Fructose 20\% (BMF) and YNB-Glucose 10\%-Fructose 10\% (BMGF) broths for the eight strains studied and the control strain with their corresponding standard errors. Equivalent letters indicate belonging to the same group at a significance level of $5 \%(\alpha=0.05)$. Values expressed in bold show the most important assemblages at the final consumer asymptotic capacity $(\boldsymbol{A})$ and consumption rate $(\boldsymbol{m})$, reflecting a better performance of the strain to achieve fermentation. 
BMG or BMF broths allowed to identify differences in sugar consumption for some of the strains. When native yeasts were studied in glucose as the only carbon source, they showed an increased development evidenced by the $m$ parameter values or the $A$ asymptotic values reached in the modeled equation, compared with development in the fructose supplemented media. Statistical differences were observed among the strains $(p<0.05)$ so, based on the obtained parameters, strains with the best profiles of glucose utilization (strain NIIF8), fructose utilization (strain ÑNM16) and mixed sugar utilization (strain ÑNM10), were chosen to continue the characterization.

The behaviour of the native strains previously selected was tested in a Pinot noir must at laboratory scale to evaluate a natural media. Profiles of weight loss are shown in Figure 1 and results of parameters obtained by modelling data of each strain are shown in Table 2. Results from the accumulated production of $\mathrm{CO}_{2}$ showed similar behaviour for the four strains; however, the parameter of the lag phase $(\lambda)$ of the indigenous strain ÑNM16 was similar to commercial strain and significantly lower than the native strain NNNM10. These minor phases of latency may be associated with a better ability of these strains to adapt to environmental conditions and quickly begin the fermentation process.

On the other hand, glucose and fructose consumption for these four selected strains was measured and modelled. Residual sugars resulting curves performed in BMGF culture media are shown in Figure 2(a) for glucose and Figure 2(b) for fructose, while resulting curves modelled in Pinot noir grape must are shown in Figure 2(c) for glucose and Figure 2(d) for fructose. Parameters obtained for the consumption are listed in Table 3. In both media, concentrations of glucose and fructose decreased rapidly at the beginning of fermentation at $28^{\circ} \mathrm{C}$ for the

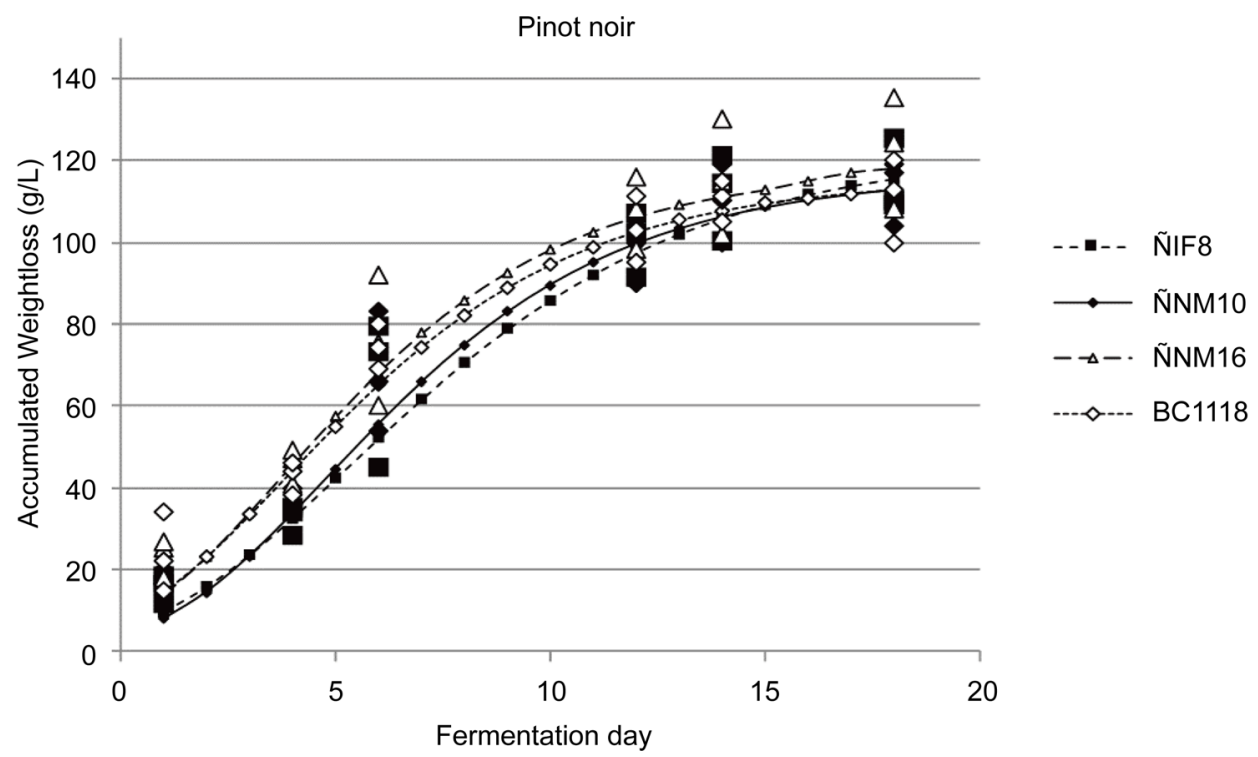

Figure 1. Modelled growth in Pinot Noir must obtained for the selected strains and the control strain.

Table 2. Modelled growth parameters obtained in Pinot noir must.

\begin{tabular}{|c|c|c|c|}
\hline \multicolumn{4}{|c|}{ Gompertz equation parameters } \\
\hline & $A$ & $m$ & $\lambda$ \\
\hline$\tilde{N} N M 10$ & $116.474 \pm 28.824^{\mathrm{a}}$ & $11.079 \pm 5.100^{\mathrm{a}}$ & $0.9720 \pm 0.398^{\mathrm{a}}$ \\
\hline$\tilde{N} I F 8$ & $122.880 \pm 28.890^{\mathrm{a}}$ & $9.849 \pm 5.096^{\mathrm{a}}$ & $0.738 \pm 0.425^{\mathrm{ab}}$ \\
\hline$\tilde{N} N M 16$ & $118.323 \pm 28.814^{\mathrm{a}}$ & $11.768 \pm 5.106^{\mathrm{a}}$ & $0.107 \pm 0.404^{\mathrm{bc}}$ \\
\hline BC1118 & $115.762 \pm 20.374^{\mathrm{a}}$ & $10.992 \pm 3.606^{\mathrm{a}}$ & $-0.027 \pm 0.290^{\mathrm{c}}$ \\
\hline
\end{tabular}

Gompertz reparametrized equation parameters obtained by modelling accumulated weightloss in Pinot noir grape juice for the three strains studied and the control strain with their corresponding standard errors. Equivalent letters indicate belonging to the same group at a significance level of $5 \%(\alpha$ $=0.05$ ). 

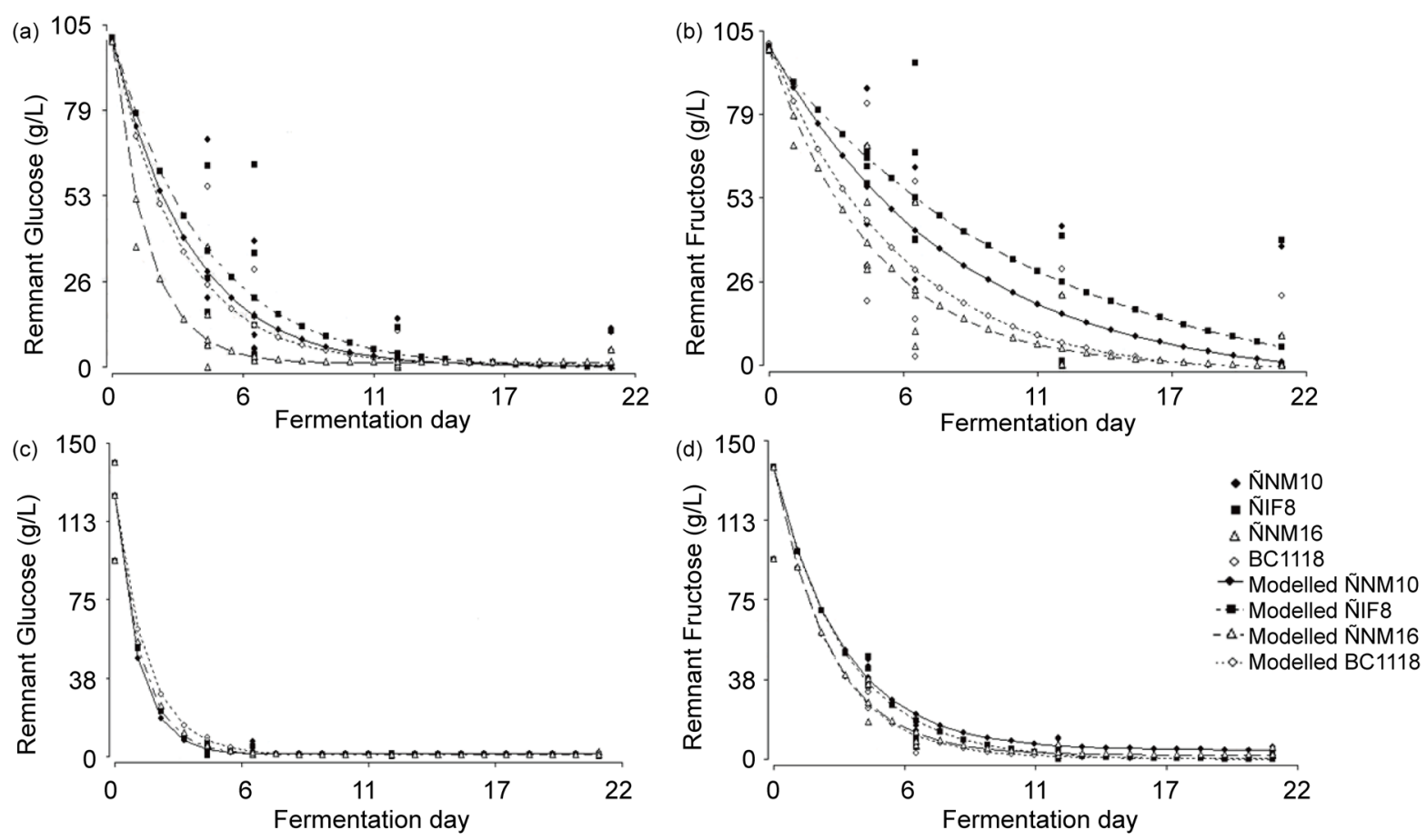

Figure 2. Modelled sugar consumption in YNB-Glucose 10\%-Fructose 10\% broth-BMGF ((a) Remnant glucose; (b) remnant fructose), and in Pinot noir must ((c) Remnant glucose and (d) remnant fructose) for the studied strains.

Table 3. Modelled hexose consumption using modified Taoukis Labuza Equation.

\begin{tabular}{|c|c|c|c|c|}
\hline & \multicolumn{4}{|c|}{ BMGF broth } \\
\hline & & $D$ & $S$ & $\boldsymbol{K}_{c}$ \\
\hline \multirow{4}{*}{ Glucose } & $\tilde{N} N M 10$ & $0.045 \pm 2.899^{\mathrm{a}}$ & $100.626 \pm 3.087^{\mathrm{a}}$ & $0.311 \pm 0.149^{b}$ \\
\hline & $\tilde{N} I F 8$ & $-0.437 \pm 3.081^{\mathrm{a}}$ & $101.300 \pm 4.391^{\mathrm{a}}$ & $0.258 \pm 0.148^{\mathrm{b}}$ \\
\hline & $\tilde{N} N M 16$ & $1.219 \pm 2.577^{\mathrm{a}}$ & $98.343 \pm 4.456^{\mathrm{a}}$ & $0.672 \pm 0.172^{a}$ \\
\hline & BC1118 & $0.716 \pm 2.019^{\mathrm{a}}$ & $99.590 \pm 4.235^{\mathrm{a}}$ & $0.352 \pm 0.107^{\mathrm{b}}$ \\
\hline \multirow{6}{*}{ Fructose } & $\tilde{N} N M 10$ & $-5.460 \pm 6.585^{\mathrm{a}}$ & $105.918 \pm 7.693^{\mathrm{a}}$ & $0.133 \pm 0.0689^{\mathrm{ab}}$ \\
\hline & $\tilde{N I F 8}$ & $-9.856 \pm 8.530^{\mathrm{a}}$ & $108.391 \pm 9.107^{\mathrm{a}}$ & $0.092 \pm 0.068^{\mathrm{b}}$ \\
\hline & $\tilde{N} N M 16$ & $-1.242 \pm 5.350^{\mathrm{a}}$ & $100.271 \pm 6.944^{\mathrm{a}}$ & $0.233 \pm 0.072^{\mathrm{a}}$ \\
\hline & BC1118 & $-3.461 \pm 3.982^{\mathrm{a}}$ & $104.403 \pm 5.046^{\mathrm{a}}$ & $0.190 \pm 0.050^{\mathrm{ab}}$ \\
\hline & \multicolumn{4}{|c|}{ Pinot noir must } \\
\hline & & $D$ & $S$ & $\boldsymbol{K}_{c}$ \\
\hline \multirow{4}{*}{ Glucose } & $\tilde{N} N M 10$ & $1.215 \pm 5.774^{\mathrm{a}}$ & $123.503 \pm 10.758^{\mathrm{a}}$ & $0.989 \pm 0.870^{\mathrm{a}}$ \\
\hline & $\tilde{N I F 8}$ & $0.738 \pm 5.819^{\mathrm{a}}$ & $123.979 \pm 10.780^{\mathrm{a}}$ & $0.887 \pm 0.615^{\mathrm{a}}$ \\
\hline & $\tilde{N} N M 16$ & $0.394 \pm 5.850^{\mathrm{a}}$ & $124.327 \pm 10.796^{\mathrm{a}}$ & $0.827 \pm 0.515^{\mathrm{a}}$ \\
\hline & BC1118 & $0.897 \pm 4.180^{\mathrm{a}}$ & $123.818 \pm 7.656^{\mathrm{a}}$ & $0.727 \pm 0.287^{\mathrm{a}}$ \\
\hline \multirow{4}{*}{ Fructose } & $\tilde{N} N M 10$ & $4.346 \pm 9.863^{\mathrm{a}}$ & $132.920 \pm 16.272^{\mathrm{a}}$ & $0.347 \pm 0.133^{\mathrm{a}}$ \\
\hline & $\tilde{N} I F 8$ & $-0.019 \pm 9.911^{\mathrm{a}}$ & $137.405 \pm 16.291^{\mathrm{a}}$ & $0.338 \pm 0.130^{\mathrm{a}}$ \\
\hline & $\tilde{N} N M 16$ & $1.950 \pm 9.562^{\mathrm{a}}$ & $135.108 \pm 16.150^{\mathrm{a}}$ & $0.427 \pm 0.153^{\mathrm{a}}$ \\
\hline & BC1118 & $0.385 \pm 6.771^{\mathrm{a}}$ & $136.702 \pm 11.423^{\mathrm{a}}$ & $0.422 \pm 0.106^{\mathrm{a}}$ \\
\hline
\end{tabular}

Parameters obtained by modelling Remnant Glucose and Fructose in YNB-Glucose 10\%-Fructose 10\% broth (BMGF) and in Pinot noir musts for the three strains studied and the control strain with their standard errors. Equivalent letters indicate identity to the same group at significance level of $5 \%$ $(\alpha=0.05)$. 
four strains studied. This was indicative of a short delay phase for all studied yeasts. When fermentations ended, remnant glucose and fructose concentration differences decreased significantly. In both fermentations, a decrease in glucose concentration preceded the decrease of fructose concentration resulting in fructose remnants higher than glucose in the sampled day. This behaviour is also reflected in glucose Kc parameter values compared with fructose $K c$ values (Table 3). While yeasts can utilize fructose concomitantly, its low consumption rates evidenced comparing $K c$ values, indicate that this is not the preferred sugar. However, the strain NNM16 showed a preference for fructose in both, synthetic medium and natural musts, statistically different $(\mathrm{p}<0.05)$. For this strain, fructose and glucose kinetic parameters were deferential to the other strains tested. Modeling $k$ for fructose consumption in BMGF media, a parameter associated to substrate utilization, rendered very small values compared to the other media analyzed, and negative values for the $D$ parameter. This fact implies that fructose is preferred for this strain. In addition, ÑNM16 evidenced a greater relative ability to quickly start the fermentation process than the other strains, native and control.

Parameters obtained for Pinot noir fermentation differed from the BMGF fermentation. These results suggest that the complex natural media from the grape must, bearing other nutritional components different from the hexoses (vitamins, polyphenols, lipids and other micronutrients) take the fermentative metabolism from the yeasts to a more robust behavior, improving hexose consumption efficiency in all the tested strains.

\subsection{Expression Analysis of Hexose Transporters along Fermentation}

Strains with better hexose consumption profiles were selected and expression of membrane transporters was studied throughout the fermentation. The expression of six hexose transporters was studied at the beginning of fermentation (before inoculation) and at fermentation days 7, 14 and 21. Isolated RNAs were retrotranscripted to cDNA and amplified by the technique of polymerase chain reaction, as described in the previous section. In parallel, cDNA from housekeeping actin protein was amplified and the relative level of the hexose transporter expression using actin as the internal control was analysed. Figure 3 shows band intensity relative values (HXT intensity/Actin intensity) for all the transporters, in day 0 and day $14^{\text {th }}$. Statistical differences in expression between transporters along the fermentation were only observed for HXT2 and HXT5 proteins (Table 4). In the $14^{\text {th }}$ day, ÑNM16 strain showed a higher expression of those transporters compared to the other studied strains.
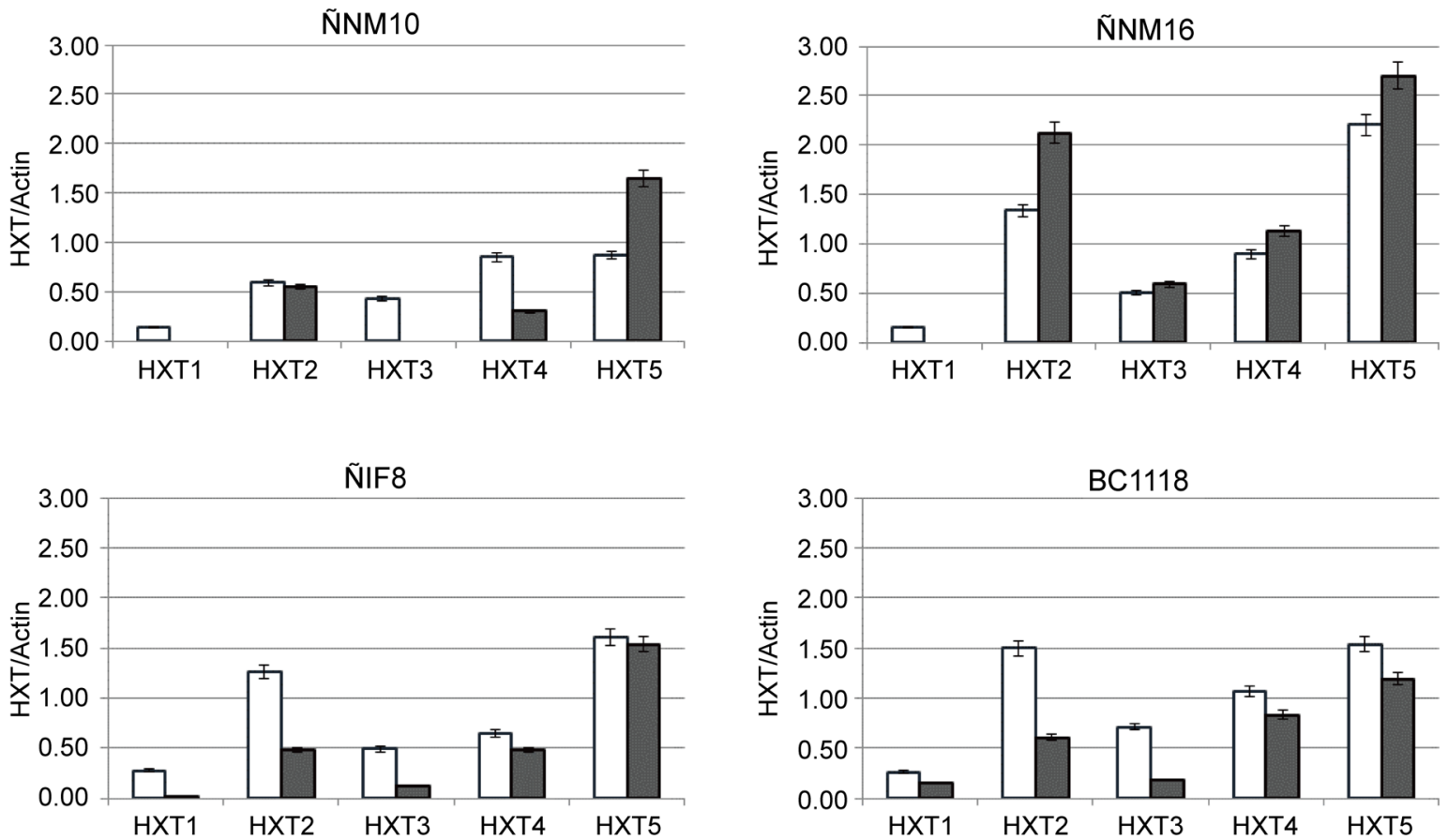

Figure 3. Relative band intensities (HXT/Actin) for the strains studied on days 0 (white bars) and 14 (grey bars) of fermentation. Individual behaviour of these transporters was analysed in YNB-Glucose 10\%-Fructose 10\%-BMGF fermentation broth. Data are given in intensity units and represent a mean \pm SD from three separate experiments. 
Table 4. Semi-quantification of transporter expression along the fermentation.

\begin{tabular}{|c|c|c|c|c|c|}
\hline & \multicolumn{5}{|c|}{ Transporter expression } \\
\hline & & Day 0 & Day 7 & Day 14 & Day 21 \\
\hline \multirow{4}{*}{ HXT2/ACTIN } & ÑNM10 & $0.545 \pm 0.138^{\mathrm{bc}}$ & $0.442 \pm 0.310^{\mathrm{bc}}$ & $0.515 \pm 0.150^{\mathrm{bc}}$ & $0.517 \pm 0.153^{\mathrm{abc}}$ \\
\hline & $\tilde{N} I F 8$ & $1.008 \pm 0.538^{\mathrm{ab}}$ & $0.410 \pm 0.127^{\mathrm{bc}}$ & $0.603 \pm 0.275^{\mathrm{abc}}$ & $0.421 \pm 0.197^{b c}$ \\
\hline & $\tilde{N} N M 16$ & $0.722 \pm 0.458^{\mathrm{abc}}$ & $1.104 \pm 0.824^{\mathrm{ab}}$ & $1.205 \pm 0.855^{\mathrm{a}}$ & $0.888 \pm 0.397^{\mathrm{abc}}$ \\
\hline & BC1118 & $0.818 \pm 0.558^{\mathrm{abc}}$ & $0.325 \pm 0.062^{c}$ & $0.547 \pm 0.279^{\mathrm{bc}}$ & $0.496 \pm 0.238^{\mathrm{bc}}$ \\
\hline \multirow{4}{*}{ HXT5/ACTIN } & $\tilde{N} N M 10$ & $0.835 \pm 0.467^{\mathrm{b}}$ & $0.364 \pm 0.085^{\mathrm{b}}$ & $0.734 \pm 0.686^{\mathrm{b}}$ & $0.381 \pm 0.205^{\mathrm{b}}$ \\
\hline & $\tilde{N} I F 8$ & $1.051 \pm 0.522^{\mathrm{ab}}$ & $0.433 \pm 0.150^{\mathrm{b}}$ & $0.918 \pm 0.475^{\mathrm{ab}}$ & $0.409 \pm 0.128^{\mathrm{b}}$ \\
\hline & $\tilde{N} N M 16$ & $1.164 \pm 0.940^{\mathrm{ab}}$ & $0.375 \pm 0.181^{\mathrm{b}}$ & $1.428 \pm 1.264^{\mathrm{a}}$ & $0.579 \pm 0.355^{\mathrm{b}}$ \\
\hline & BC1118 & $1.231 \pm 0.454^{\mathrm{ab}}$ & $0.433 \pm 0.044^{\mathrm{b}}$ & $1.121 \pm 0.387^{\mathrm{ab}}$ & $0.734 \pm 0.829^{\mathrm{b}}$ \\
\hline
\end{tabular}

Relative band intensities (HTX/Actin) for each of the studied strains and the control strain along the fermentations. Data are given in intensity units and represent a mean \pm SD from three separate experiments. Equivalent letters indicate identity to the same group at a significance level of $5 \%(\alpha=$ 0.05).

It is noteworthy to say that in none of the sampled days and under any amplification conditions tested, transporters $H X T 6 / 7$ gene expression was detected. This may indicate a possible change in the sequence for the native strains, compared to the reference strain model from which the primers were generated, a fact that would deserve further investigation. Polymorphisms analysis has been carried out in $S$. cerevisiae transporters genes, and some of the sequences show a high number of substitutions, which could explain our results [28] [29].

\section{Discussion}

This work was carried out under the hypothesis that $S$. cerevisiae yeast strains isolated from vineyards or cellars from the North Patagonian region may contribute in fermentations to a better substrate consumption, rendering higher quality local wines. Under this framework, eight native S. cerevisiae strains were analysed in must sugar utilization using physiological and molecular methods to evaluate their potential application in local vinicultural processes.

Rising ethanol concentrations towards the end of the fermentation may affect hexose transport affinity and consumption, being fructose metabolization more affected than glucose metabolization, possibly generating stuck or sluggish fermentations, a major problem in the global wine industry [30] [31]. Under these conditions, an excessively high fructose to glucose ratio is observed, and since fructose is approximately twice as sweet to taste as glucose, excess fructose can cause undesirable sweetness in wines [32]-[34]. Therefore, one of the challenges in strain selection for wine fermentation is to find fructophilic individuals to conduct or collaborate in the process.

In our assays, this glucose/fructose preference in BMGF broths was also observed showing the glycophilic character of the S. cerevisiae autochthonous species, extensively described in literature [5] [30]. However, one of the native strains, NNM16, was selected due to its fermentative behavior with a better performance in BMF broths. This strain evidenced differential parameter values for modeled growth in fructose and modeled sugar consumption compared with the other studied strains, revealing a preference for fructose over glucose, implying its important enological potential.

According to the literature, differences in glucose or fructose utilization are attributable to differences in hexose transport [4] or in hexokinase kinetic properties [35]. To analyze the differences in hexose consumption found in ÑN16 native strain, hexose transporter molecular expression was evaluated during broth fermentation. Interestingly, NNM16 strain showed statistical differences in Hxt2p and Hxt5p expression, which was higher towards the end of the fermentation (day $14^{\text {th }}$ ) compared to the other strains, a fact that initially presents contrary to what was observed in other studies [36]. HXT2 gene encodes a high affinity glucose transporter that is expressed under conditions of glucose limitation contributing to yeast survival under this stress situation, [37], and is the better suited transporter for the utilization of very low external hexose levels [7], Hxt2p was found 
highly expressed in $2 \%$ fructose cultures than in $2 \%$ glucose cultures and strongly induced by media alkalization [37]. ÑNM16 over expressing Hxt2p may present as an adaptive variant to develop in stress conditions and nutritional deficient media.

On the other hand, HXT5 gene is expressed upon a decrease in the growth rate of cells when glucose is still available in the medium, presenting a maximal expression upon glucose depletion [38] [39]. The abundance of Hxt5p during nutrient limitation suggests that it is involved in the generation of an intracellular signal of nutrient availability [40]. When cells endure starvation periods, they might anticipate glucose re-exposure by expressing the Hxt5p transporter, an advantage that could enable cells to take up glucose instantly after new hexose supplementation. Cells presenting this improved metabolic pathway of energy management efficiency may outcompete other yeasts [41]. These transcriptional regulations are physiologically relevant suggesting an enhanced metabolism to endure stressing conditions. In addition, Hxt5p is associated to glycogen or trehalose production under stress conditions towards the conclusion of the fermentation, as the observed for all the tested strains, because increasing osmolality of the growth medium also induces expression of HXT5. Trehalose formation depends on glucose availability and Hxt5p may provide glucose to fulfil disaccharide production purposes [38]. Starved cells accumulating carbon hydrates suggest that Hxt5p could be responsible for this glucose uptake activity [42].

\section{Conclusion}

Autochthonous ÑNM16 may be adapted to overexpress proteins that allow the strain to survive in the stressful climate from North Patagonia and to compete with other strains for the space. These data suggest that the initial work hypothesis could be accepted. From a technological point of view, S. cerevisiae ÑNM16 presented interesting metabolic features to be considered for enological application. In future studies, fermentation capacity at pilot scale and endurance for the dehydration/rehydration process involved in commercial yeasts lyophilizing treatments should also be tested.

\section{Acknowledgements}

The authors gratefully acknowledge support from Social and Technological Development Project PDTS $\mathrm{N}^{\circ} 173$, CIN-CONICET (Convocatoria 2014) and Universidad Nacional del Comahue (PROIN L003).

\section{References}

[1] Fleet, G.H. (2007) Wine. In: Doyle, M.P. and Beuchat, L.R., Eds., Food Microbiology: Fundamentals and Frontiers, 3rd Edition, ASM Press, Washington DC, 863-890. http://dx.doi.org/10.1128/9781555815912.ch41

[2] Pretorius, I. (2000) Tailoring Wine Yeast for the New Millennium: Novel Approaches to the Ancient Art of Winemaking. Yeast, 15, 675-629. http://dx.doi.org/10.1002/1097-0061(20000615)16:8<675::AID-YEA585>3.0.CO;2-B

[3] Dequin, S. (2001) The Potential of Genetic Engineering for Improving Brewing, Wine-Making and Baking Yeasts. Applied Microbiology and Biotechnology, 56, 577-588. http://dx.doi.org/10.1007/s002530100700

[4] Guillaume, C., Delobel, P., Sablayrolles, J.M. and Blondin, B. (2007) Molecular Basis of Fructose Utilization by the Wine Yeast Saccharomyces cerevisiae: A Mutated HXT3 Allele Enhances Fructose Fermentation. Applied and Environmental Microbiology, 73, 2432-2439. http://dx.doi.org/10.1128/AEM.02269-06

[5] Tronchoni, J., Arroyo-López, A., Gamero, N., Barrio, E. and Querol, A. (2009) Differences in the Glucose and Fructose Consumption Profiles in Diverse Saccharomyces Wine Species and Their Hybrids during Grape Juice Fermentation. International Journal of Food Microbiology, 134, 237-243. http://dx.doi.org/10.1016/j.ijfoodmicro.2009.07.004

[6] Suárez-Lepe, J.A. and Morata, A. (2012) New Trends in Yeast Selection for Winemaking. Trends in Food Science and Technology, 23, 39-50. http://dx.doi.org/10.1016/j.tifs.2011.08.005

[7] Boles, E. and Hollenberg, C. (1997) The Molecular Genetics of Hexose Transport in Yeast. FEMS Microbiology Reviews, 21, 85-111. http://dx.doi.org/10.1111/j.1574-6976.1997.tb00346.x

[8] Özcan, S. and Johnston, N. (1999) Function and Regulation of Yeast Hexose Transporters. Microbiology and Molecular Biology Reviews, 63, 554-569.

[9] Reifenberger, E., Boles, E. and Ciriacy, M. (1997) Kinetic Characterization of Individual Hexose Transporters of Saccharomyces cerevisiae and Their Relation to the Triggering Mechanisms of Glucose Repression. European Journal of Biochemistry, 245, 324-333. http://dx.doi.org/10.1111/j.1432-1033.1997.00324.x 
[10] Lin, B., Zhao, X., Zhang, Q., Ma, L. and Bai, F. (2010) Cloning of the Promoter Region of the Trehalose-6-Phosphate Synthase Gene TPS1 of the Self-Flocculating Yeast and Exploration of the Promoter Activity on Ethanol Stress. Chinese Journal of Biotechnology, 26, 1014-1018.

[11] Palma, M., Madeira, S.C., Mendes-Ferreira, A. and Sá-Correia, I. (2012) Impact of Assimilable Nitrogen Availability in Glucose Uptake Kinetics in Saccharomyces cerevisiae during Alcoholic Fermentation. Microbial Cell Factories, 11, 99. http://dx.doi.org/10.1186/1475-2859-11-99

[12] Llorente, A. and Casazza, M. (2005) El vino y su industria.

[13] Catania, C. and Avagnina, S. (2010) La Interpretación Sensorial del Vino. INTA-Caviar Bleu, Mendoza.

[14] Capece, A., Romaniello, R., Siesto, G., Pietrafesa, R., Massari, C., Poeta, C. and Romano, P. (2010) Selection of Indigenous Saccharomyces cerevisiae Strains for Nero d'Avola Wine and Evaluation of Selected Starter Implantation in Pilot Fermentation. International Journal of Food Microbiology, 144, 187-192. http://dx.doi.org/10.1016/j.ijfoodmicro.2010.09.009

[15] Gilbert, J.A., van der Lelie, D. and Zarraonaindia, I. (2013) Microbial Terroir for Wine Grapes. Proceedings of the National Academy of Sciences of the United States of America, 111, 5-6. http://dx.doi.org/10.1073/pnas.1320471110

[16] Vigentini, I., De Lorenzis, G., Fabrizio, V., Valdetara, F., Faccincani, M., Panont, C.A., Picozzi, C., Imazio, S., Failla, O. and Foschino, R. (2015) The Vintage Effect Overcomes the Terroir Effect: A Three-Year Survey on the Wine Yeast Biodiversity in Franciacorta and Oltrepò Pavese, Two Northern Italian Vine-Growing Areas. Microbiology, 161, 362373. http://dx.doi.org/10.1099/mic.0.000004

[17] Caballero, A. (2008) Informe Final PFI.P Agencia UNComahue. Neuquén: s.n.

[18] Lopes, C.A., van Broock, M., Querol, A. and Caballero, A.C. (2002) Saccharomyces cerevisiae Wine Yeast Populations in a Cold Region in Argentinean Patagonia. A Study at Different Fermentation Scales. Journal of Applied Microbiology, 93, 608-615. http://dx.doi.org/10.1046/j.1365-2672.2002.01738.x

[19] White, T.J., Bruns, T.D., Lee, S.B. and Taylor, J.W. (1990) Amplification and Direct Sequencing of Fungal Ribosomal RNA Genes for Phylogenetics. In: Innis, M.A., Gelfand, D.H., Sninsky, J.J. and White, T.J., Eds., PCR-Protocols and Applications-A Laboratory Manual, Academic Press, Cambridge, 315-322. http://dx.doi.org/10.1016/b978-0-12-372180-8.50042-1

[20] Kurtzman, C.P. and Robnett, C.J. (1998) Identification and Phylogeny of Ascomycetous Yeasts from Analysis of Nuclear Large Subunit (26S) Ribosomal DNA Partial Sequences. Antonie van Leeuwenhoek, 73, 331-371. http://dx.doi.org/10.1023/A:1001761008817

[21] Tamura, K., Stecher, G., Peterson, D., Filipski, A. and Kumar, S. (2013) MEGA6: Molecular Evolutionary Genetics Analysis Version 6.0. Molecular Biology and Evolution, 30, 2725-2729. http://dx.doi.org/10.1093/molbev/mst197

[22] Querol, A., Barrio, E., Huerta, T. and Ramón, D. (1992). Molecular Monitoring of Wine Fermentations Conducted by Active Dry Yeast Strains. Applied and Environmental Microbiology, 58, 2948-2953.

[23] R Core Team (2014) R: A Language and Environment for Statistical Computing. http://www.R-project.org/

[24] Zwietering, M., Jongenburger, I., Rombouts, F. and Van’t Riet, K. (1990) Modeling of the Bacterial Growth Curve. Applied and Environmental Microbiology, 56, 1875-1881.

[25] Taoukis, P., Labuza, T. and Saguy, I. (1997) Kinetic of Food Deterioration and Shelf-Life Prediction. In: Valentas, K., Rotstein, E. and Singh, R., Eds., Handbook of Food Engineering Practice, CRC Press, Boca Ratón, 361-404.

[26] Arroyo-López, F., Bautista-Gallego, J., Durán-Quintana, M. and Garrido-Fernández, A. (2008) Effects of Ascorbic Acid, Sodium Metabisulfite and Sodium Chloride on Freshness Retention and Microbial Growth during the Storage of Manzanilla-Aloren a Cracked Table Olive. LWT Food Science and Technology, 41, 551-560. http://dx.doi.org/10.1016/j.lwt.2007.05.016

[27] Lee, Y. and Lee, C. (2008) Transcriptional Response According to Strength of Calorie Restriction in Saccharomyces cerevisiae. Molecules and Cells, 26, 299-307.

[28] Karpel, J.E., Place, W.R. and Bisson, L.F. (2008) Analysis of the Major Hexose Transporter Genes in Wine Strains of Saccharomyces cerevisiae. American Journal of Enology and Viticulture, 59, 265-275.

[29] Oliva Hernández, A.A., Taillandier, P., Reséndez Pérez, D., Narváez Zapata, J.A. and Larralde Corona, C.P. (2013) The Effect of Hexose Ratios on Metabolite Production in Saccharomyces cerevisiae Strains Obtained from the Spontaneous Fermentation of Mescal. Antonie van Leeuwenhoek, 103, 833-843. http://dx.doi.org/10.1007/s10482-012-9865-1

[30] Berthels, N.J., Cordero Otero, R.R., Bauer, F.F., Thevelein, J.M. and Pretorius, I.S. (2004) Discrepancy in Glucose and Fructose Utilisation during Fermentation by Saccharomyces cerevisiae Wine Yeast Strains. FEMS Yeast Research, 4, 683-689. http://dx.doi.org/10.1016/j.femsyr.2004.02.005

[31] Santos, J., Sousa, M.J., Cardoso, H., Inácio, J., Silva, S., Spencer-Martins, I. and Leão, C. (2008) Ethanol Tolerance of 
Sugar Transport, and the Rectification of Stuck Wine Fermentations. Microbiology, 154, 422-430. http://dx.doi.org/10.1099/mic.0.2007/011445-0

[32] Boulton, R.B., Singleton, V.L., Bisson, L.F. and Kunkee, R.E. (1996) Principles and Practices of Winemaking. Chapman \& Hall, New York.

[33] Gafner, J. and Schultz, M. (1996) Impact of Glucose-Fructose Ratio on Stuck Fermentations: Practical Experiences to Restart Stuck Fermentation. Viticulture and Enology Science, 51, 214-218.

[34] Bisson, L.F. (1999) Stuck and Sluggish Fermentations. American Journal of Enology and Viticulture, 50, 107-119.

[35] Berthels, N.J., Cordero Otero, R.R., Bauer, F.F., Pretorius, I.S. and Thevelein, J.M. (2008) Correlation between Glucose/Fructose Discrepancy and Hexokinase Kinetic Properties in Different Saccharomyces cerevisiae Wine Yeast Strains. Applied Microbiology and Biotechnology, 77, 1083-1091. http://dx.doi.org/10.1007/s00253-007-1231-2

[36] Perez, M., Luyten, K., Michel, R., Riou, C. and Blondin, B. (2005) Analysis of Saccharomyces cerevisiae Hexose Carrier Expression during Wine Fermentation: Both Low- and High-Affinity Hxt Transporters Are Expressed. FEMS Yeast Research, 5, 351-361. http://dx.doi.org/10.1016/j.femsyr.2004.09.005

[37] Ruiz, A., Serrano, R. and Ariño, J. (2008) Direct Regulation of Genes Involved in Glucose Utilization by the Calcium/Calcineurin Pathway. The Journal of Biological Chemistry, 20, 13923-13933. http://dx.doi.org/10.1074/jbc.M708683200

[38] Verwaal, R., Paalman, J., Hogenkamp, A., Verkleij, A., Verrips, C. and Boonstra, J. (2002) HXT5 Expression Is Determined by Growth Rates in Saccharomyces cerevisiae. Yeast, 19, 1029-1038. http://dx.doi.org/10.1002/yea.895

[39] Verwaal, R., Arako, M., Kapur, R., Verkleij, A.J., Theo Verrips, C. and Boonstra, J. (2004) HXT5 Expression Is under Control of STRE and HAP Elements in the HXT5 Promoter. Yeast, 21, 747-757. http://dx.doi.org/10.1002/yea.1106

[40] Diderich, J., Schuurmans, J., Van Gaalen, M., Kruckeberg, A. and Van Dam, K. (2001) Functional Analysis of the Hexose Transporter Homologue HXT5 in Saccharomyces cerevisiae. Yeast, 18, 1515-1524. http://dx.doi.org/10.1002/yea.779

[41] Bermejo, C., Haerizadej, F., Sadoine, M., Chermak, D. and Frommer, W. (2013) Differential Regulation of Glucose Transport Activity in Yeast by Specific cAMP Signatures. Biochemical Journal, 452, 489-497. http://dx.doi.org/10.1042/BJ20121736

[42] Bermejo, C., Haerizadeh, F., Takanaga, H., Chermak, D. and Frommer, W. (2010) Dynamic Analysis of Cytosolic Glucose and ATP Levels in Yeast with Optical Sensors. Biochemical Journal, 432, 399-406. http://dx.doi.org/10.1042/BJ20100946

\section{Submit or recommend next manuscript to SCIRP and we will provide best service for you:}

Accepting pre-submission inquiries through Email, Facebook, LinkedIn, Twitter, etc.

A wide selection of journals (inclusive of 9 subjects, more than 200 journals)

Providing 24-hour high-quality service

User-friendly online submission system

Fair and swift peer-review system

Efficient typesetting and proofreading procedure

Display of the result of downloads and visits, as well as the number of cited articles

Maximum dissemination of your research work

Submit your manuscript at: http://papersubmission.scirp.org/ 